\title{
Variability in Plasma FGF21 Levels in Rats Fed A Standard 15\% Protein Diet is not Sensitive Enough to Reflect Differences in Protein Requirements
}

\author{
Joséphine Gehring* , Dalila Azzout-Marniche and Patrick C Even \\ Université Paris-Saclay, AgroParisTech, INRAE. UMR PNCA, 75005, Paris, France
}

*Corresponding author: Joséphine Gehring, Université Paris-Saclay, AgroParisTech, INRAE, UMR PNCA, 75005, Paris, France

Received: 槶October 19, 2020

Published: 些 October 27, 2020

Keywords: Inter-Individual Variability; Plasma FGF21 Level; Protein Level; Self-Selection Diet

Abbreviations: FGF21: Fibroblast Growth Factor 21; SEM: Standard Error of the Mean

\section{Introduction}

Fibroblast growth factor 21 (FGF21) is a hepatokine member of a subfamily of "fibroblast growth factors" that responds to multiple metabolic stresses as protein deficiency [1-4]. FGF21 is produced in various tissues but the FGF21 circulating form is primarily of hepatic origin [1,2]. FGF21 affects numerous metabolic and behavioural parameters, and in particular, increases appetite for protein in subjects fed a protein-deprived diets $[5,6]$. In a recent still unpublished study, we observed that plasma FGF21 levels were higher in adult male Wistar rats fed a standard diet, formulated according the AIN93 recommendations for rats' feed, containing $15 \%$ protein by energy [7] than in rats fed a $30 \%$ protein diet. In addition, inter-individual variability of plasma FGF21 levels was larger in rats fed the standard $15 \%$ protein diet than in rats fed the $30 \%$ protein diet. We therefore considered the hypothesis that higher levels and inter-individual variability in plasma FGF21 levels in rats fed a standard $15 \%$ protein diet would reflect the variability in protein requirements between individuals and thus, that measurement of plasma FGF21 levels can be used as a simple, rapid, and minimally-invasive test to estimate the adequacy of protein intake.

Dietary self-selection is a method that has been largely used in farm animals and laboratory rodents to study the requirements for macronutrients (carbohydrates, lipids and proteins), vitamins and minerals $[8,9]$. Many studies using this method, in our lab and others, showed that rats self-selecting between a protein diet and a protein-free diet often ingest up to $30-50 \%$ of total energy intake as protein [10-15], so much higher than the level considered as sufficient for an optimal growth in adult rats (10-15\% by energy), which comforted our hypothesis that $15 \%$ dietary protein was possibly not the optimal dietary content.

The objective of this study was to verify that variability in plasma FGF21 levels in rats fed a standard 15\% protein diet was indicative of differences in protein requirements. To this end, we have analyzed the relationship between FGF21 levels, and the level of protein subsequently selected during self-selection between a protein diet and a protein-free diet.

\section{Experimental Procedure}

24 adult male rats $(215-240 \mathrm{~g})$ of the Wistar RccHan strain (ENVIGO) were used and individually housed $\left(22^{\circ} \mathrm{C} \pm 1{ }^{\circ} \mathrm{C}, 12 / 12\right.$ L/D, cycle lights on at 08:00). After 1 week of adaptation to the laboratory conditions, the rats were fed for 12 days (Basal period) a standard diet formulated according to the AIN93 requirements [7] that contained 15\% protein (15P); then, for 28 days (Choice period), 6 rats (Control group) continued to be fed with the standard diet and 18 (Self-selecting group) were given a choice between a pure protein diet (100P) and a protein-free diet containing a mix of fat (soy oil) and carbohydrate (corn starch and sucrose) in which carbohydrate amounted $60 \%$ by energy. The diets were provided, as necessary. 
The food pellets were prepared twice a week by mixing the macronutrients, vitamins, and mineral mix with the amount of water required to make a thick dough. Food intake (g/day) was measured twice a week and converted in $\mathrm{kJ} /$ day based on the energy content of the diets (Table 1 ).

Table 1: Composition and energy content of the 3 used diets.

\begin{tabular}{|c|c|c|c|}
\hline & 100P & 60C & 15P \\
\hline Whole milk protein (g/kg) & 911 & & 166 \\
\hline Corn starch (g/kg) & & 620 & 506 \\
\hline Sucrose (g/kg) & & 100 & 81.7 \\
\hline Soy oil (g/kg) & & 183 & 149 \\
\hline Mineral compound AIN93M (g/kg) & 31.9 & 35.0 & 35.0 \\
\hline Vitamin compound AIN93Vx (g/kg) & 9.11 & 10.0 & 10.0 \\
\hline Cellulose (g/kg) & 45.6 & 50.0 & 50.0 \\
\hline Choline chloride (g/kg) & 2.10 & 2.30 & 2.30 \\
\hline Energy (kJ/g) & 15 & 18.4 & 17.4 \\
\hline Protein/energy ratio (\%) & 100 & - & 15 \\
\hline Carbohydrate/energy ratio (\%) & - & 60 & 52.4 \\
\hline Fat/energy ratio (\%) & - & 40 & 32.6 \\
\hline
\end{tabular}

100P: diet containing only proteins; 60C: protein-free diet containing only lipids and carbohydrates and in which carbohydrates amounted $60 \%$ by energy; 15P: standard diet containing $15 \%$ of protein by energy.

Blood samples $(0.5 \mathrm{~mL})$ were collected from the tail vein in EDTA tubes: once during the basal period and once during the choice period. Blood collection was made in the morning (10:0012:00) in rats that were not previously fasted. Blood samples were centrifuged $\left(5000 \mathrm{~g}, 15 \mathrm{~min}, 4^{\circ} \mathrm{C}\right)$ and the plasma stored at $-20^{\circ} \mathrm{C}$. Plasma FGF21 levels (pg/ml) were measured by ELISA tests using commercial kits from Bio Vendor (Mouse/Rat FGF-21 ELISA RD291108200R).

\section{Statistical Analysis}

Statistical tests were performed using RStudio software, 2015. Changes in protein intake and plasma FGF21 level were compared using mixed two-factor ANOVA tests (parameter group*period), which were followed by the main effects analysis by Bonferroni adjusted pairwise comparisons. Values are presented as means \pm standard error of the mean (SEM). Linear regression analysis was used to study the link between plasma FGF21 levels during the basal period and protein intake during the choice period and was performed using Excel software. Significance of correlations was assessed using the Pearson correlation coefficient. A threshold of $\mathrm{P} \leq 0.05$ was chosen as significant.

\section{Results and Discussion}

Protein intake was similar between the control and selfselecting group during the basal period but increased by $80 \%$ in the self-selecting group during the choice period $(+37.8 \mathrm{~kJ} / \mathrm{d}$, $\mathrm{p}<0.0001$ ) (Figure 1). This response significantly increased the contribution of protein to total energy intake from $15.0 \%$ to $23.5 \%$ ( $\mathrm{p}<0.001$ ). Mean plasma FGF21 levels averaged $\sim 1,100 \mathrm{pg} / \mathrm{mL}$ in both groups during the basal period and decreased to $131 \mathrm{pg} / \mathrm{mL}$ in self-selecting group during the choice period $(\mathrm{P}<0.001)$ (Figure 2). The variability of plasma FGF21 concentrations measured in rats fed a control $15 \%$ protein diet is not predictive of interindividual differences in protein requirements (Figure 3).

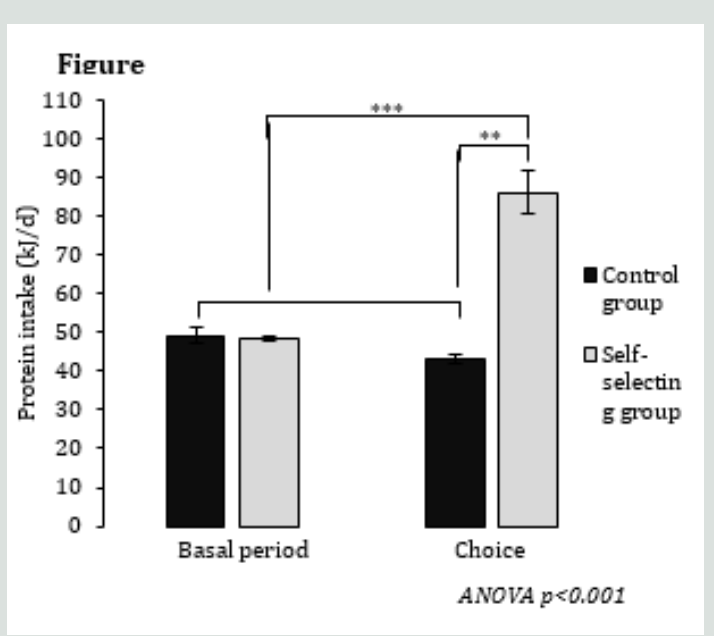

Figure 1: Protein intake $(\mathrm{kJ} / \mathrm{d})$ according to diet group and period.

$\left({ }^{*}: 0.05 ;{ }^{* *}: 0.01 ;{ }^{* * *}: 0.001 ;{ }^{* * * *}: 0.0001\right)$ Values are represented as means $\pm S E M$, only the $\mathrm{p}$-value of the interaction of ANOVA tests are indicated. 


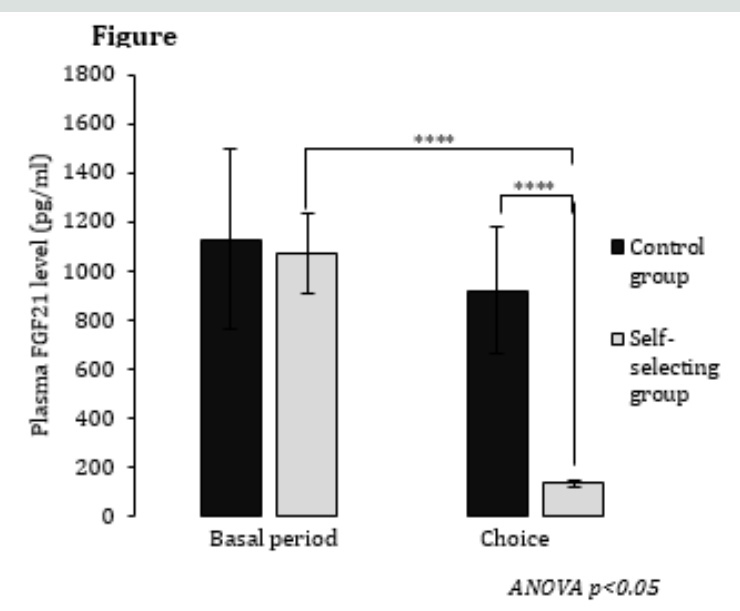

Figure 2: FGF21 level in plasma $(\mathrm{pg} / \mathrm{ml})$ according to diet group and period.

$\left({ }^{*}: 0.05 ;{ }^{* *}: 0.01 ;{ }^{* * *}: 0.001 ;{ }^{* * * *}: 0.0001\right)$ Values are represented as means $\pm S E M$, only the $\mathrm{p}$-value of the interaction of ANOVA tests are indicated.

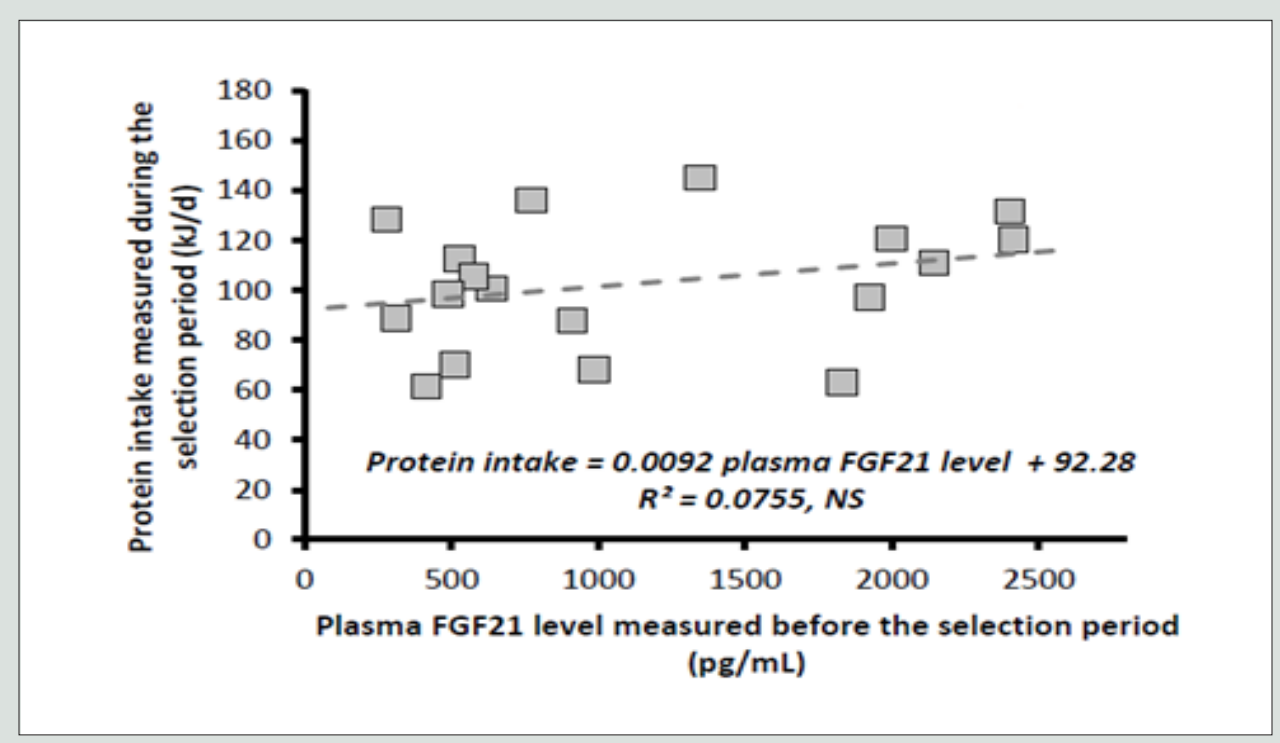

Figure 3: Protein intake $(\mathrm{kJ} / \mathrm{d})$ during the choice period as a function of plasma FGF21 levels during the basal period in the self-selecting group.

\section{Conclusion}

In conclusion, inter-individual variability in plasma FGF21 levels in rats fed a standard $15 \%$ protein diet did not appear to be a parameter sensitive enough to reflect inter-individual differences in protein requirements. Therefore, plasma FGF21 level cannot be used as a test to determine inter-individual variability in protein requirements in individuals. Nevertheless we observed that plasma FGF21 levels in P15 fed rats were $\sim 7$ fold higher than in selfselecting rats ingesting $23.5 \%$ protein, which points on the fact that changes in plasma FGF21 levels are very sensitive to dietary protein intake, even when protein intake is well above essential protein requirements ( $\sim 8-10 \%$ in adult male rats).

\section{Acknowledgments}

The authors thank Morgane Dufay for her precious help in the maintenance of the rats during the study.

\section{References}

1. Staiger H, Keuper M, Berti L, Hrabě de Angelis M, Häring HU (2017) Fibroblast Growth Factor 21-Metabolic Role in Mice and Men. Endocr Rev 38(5): 468-488. 
2. Kathleen R Markan, Meghan C Naber, Magdalene K Ameka, Maxwell D Anderegg, David J Mangelsdorf, et al. (2014) Circulating FGF21 Is Liver Derived and Enhances Glucose Uptake During Refeeding and Overfeeding. Diabetes 63(12): 4057-4063.

3. Catherine Chaumontet, Dalila Azzout-Marniche, Anne Blais, Julien Piedcoq, Daniel Tomé, et al. (2019) Low-protein and methionine, highstarch diets increase energy intake and expenditure, increase FGF21, decrease IGF-1, and have little effect on adiposity in mice. Am J PhysiolRegul Integr Comp Physiol 316(5): R486-R501.

4. Fisher FM, Maratos-Flier E (2016) Understanding the Physiology of FGF21. Annu Rev Physiol 78(1): 223-241.

5. Tomé D, Chaumontet C, Even PC, Darcel N, Azzout-Marniche D (2019) Protein status modulates the rewarding value of foods and meals to maintain an adequate protein intake. Physiol Behav 206: 7-12.

6. Tomé D, Chaumontet C, Even PC, Darcel N, Thornton SN, et al. (2020) Protein Status Modulates an Appetite for Protein to Maintain a Balanced Nutritional State-A Perspective View. J Agric Food Chem 68(7): 18301836.

7. Reeves PG, Nielsen FH, Fahey GC (1993) AIN-93 purified diets for laboratory rodents: final report of the American Institute of Nutrition ad hoc writing committee on the reformulation of the AIN-76A rodent diet J Nutr 123(11): 1939-1951.

8. Richter CP, Holt Jr LE, Barelare Jr B (1938) Nutritional requirements for normal growth and reproduction in rats studied by the self-selection method. American Journal of Physiology 122: 734-744.
9. George Collier Alan I, Leshner, Robert L Squibb (1969) Dietary selfselection in active and non-active rats. Physiol Behav 4(1): 79-82.

10. Musten B, Peace D, Anderson GH (1974) Food intake regulation in the weanling rat: self-selection of protein and energy. J Nutr 104(5): 563572.

11. Castonguay TW, Hartman WJ, Fitzpatrick EA, Stern JS (1982) Dietary self-selection and the Zucker rat. J Nutr 112(4): 796-800.

12. Mullen BJ, Martin RJ (1992) Novel approach to diet design for determining macronutrient preference. Pharmacol Biochem Behav 42(2): 343-346.

13. Jean C, Fromentin G, Tomé D, Larue-Achagiotis C (2002) Wistar rats allowed to self-select macronutrients from weaning to maturity choose a high-protein, high-lipid diet. Physiol Behav 76(1): 65-73.

14. Makarios-Lahham L, Roseau SM, Fromentin G, Tome D, Even PC (2004) Rats free to select between pure protein and a fat-carbohydrate mix ingest high-protein mixed meals during the dark period and protein meals during the light period. J Nutr 134(3): 618-624.

15. Azzout-Marniche D, Chalvon-Demersay T, Pimentel G, Catherine Chaumontet, Nachiket A Nadkarni, et al. (2016) Obesity-prone high-fatfed rats reduce caloric intake and adiposity and gain more fat-free mass when allowed to self-select protein from carbohydrate:fat intake. Am J Physiol-Regul Integr Comp Physiol 310(11): R1169-R1176.

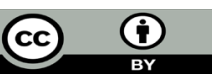

This work is licensed under Creative

Commons Attribution 4.0 License

To Submit Your Article Click Here:

Submit Article

DOI: $10.32474 / A D 0.2020 .03 .000154$ 